\title{
Comparison of the Optical and Electrical Properties of Al-Doped ZnO Films Using a Lorentz Model
}

\author{
Jin-Cherng Hsu ${ }^{1,2, *}$ and Yu-Yun Chen ${ }^{2}$ \\ 1 Department of Physics, Fu Jen Catholic University, No.510 Zhongzheng Rd., Xinzhuang Dist., \\ New Taipei City 24205, Taiwan \\ 2 Graduate Institute of Applied Science and Engineering, Fu Jen Catholic University, No. 510 Zhongzheng Rd., \\ Xinzhuang Dist., New Taipei City 24205, Taiwan; nick73328@hotmail.com \\ * Correspondence: 054326@mail.fju.edu.tw; Tel.: +886-2-2905-3765
}

Received: 29 October 2018; Accepted: 17 December 2018; Published: 21 December 2018

check for updates

\begin{abstract}
In this research, zinc oxide $(\mathrm{ZnO})$ films are doped with various amounts of $\mathrm{Al}$ dopants, from 0 to 13 at.\%, using ion-beam co-sputtering for $\mathrm{Zn}$ and $\mathrm{Al}$ metallic targets at room temperature. The Al-doped $\mathrm{ZnO}$ (AZO) films appear to have lower transmittances in the UV and near-IR ranges. The electrical and optical properties of each film are successfully analyzed by using the spectroscopic ellipsometry of two Lorentz oscillators for the two lower transmittances. The optimal AZO film is deposited with an Al-dopant of 1.5 at.\% at an oxygen partial pressure of $0.12 \mathrm{mTorr}$; it has the smallest resistivity of $7.8 \times 10^{-4} \Omega \mathrm{cm}$ and high transmittance of $>80 \%$ in the visible regions. The free carrier concentration and mobility evaluated using ellipsometry are different from those measured using the Hall effect. This phenomenon was the result of the grain boundary scattering due to the small $\sim 20$-nm grain size of the AZO film used in this study.
\end{abstract}

Keywords: $\mathrm{ZnO}$; Al-doped $\mathrm{ZnO}$; ellipsometry; Lorentz oscillators; Hall effect; grain boundary scattering

\section{Introduction}

Conductive transparent oxide (CTO) films have high transmittance in the visible light region and high reflectance in the IR region in combination with a high conductivity; therefore, they are widely used in electronic and optical devices. Zinc oxide $(\mathrm{ZnO})$ film, a CTO film, has a hexagonal wurtzite structure [1]. It is an n-type semiconductor and has a direct wide bandgap of approximately $3.4 \mathrm{eV}$. The existence of electron carriers is due to oxygen vacancies and intrinsic defects [2,3]. $\mathrm{ZnO}$ films exhibit high visible transparency and low resistivity, which, however, is still greater than that of indium tin oxide (ITO). The Al dopant, a group-III element, has become the most promising n-type semiconductor candidate because of its high thermal stability [4-7]. Al-doped $\mathrm{ZnO}$ (AZO) film has played a significant role in the development of optoelectronic devices [8-11]. It is not only highly visible transparent but also has metal-like electrical conductivity [1]. Many researchers have evaluated its optical and electrical properties. Spectroscopic ellipsometry is one of the methods used to determine the thickness, surface roughness, and optical constants using various dispersion models [12-14].

This study includes reviewed data from our previous studies [15-19], wherein AZO films were investigated using spectroscopic ellipsometry with a parametric model containing two Lorentz oscillators. The model assumes that the response of the electron carrier driven by the electric field in the film is similar to that of a mass harmonically driven by a spring combined with a dissipative force. In this comparison, the spring represents the electrostatic force on the electron caused by all the other electrons and nuclei in the solid, and the dissipative force represents the energy loss due to the emission of a photon. This model treats the electron as a particle that has mass orbits with a given 
trajectory and a certain amount of kinetic energy. Although this model violates the allowed quantum energy level, the Lorentz model still accurately depicts the optical constants of many optical materials and resonant absorptive processes.

The optical spectrum exhibits two lower transmittances in the near-IR range due to the conductive property of the electron carriers in the AZO film, and in the UV range due to the dielectric property of the optical absorption. The Lorentz oscillator for the zero-energy-centered free electron absorption in the near-IR range is usually reduced to the Drude model, which is very useful for transparent conductive oxides [20]. Thus, in this study, we used a parametric model with two Lorentz oscillators for the optical dispersion, instead of using Cauchy and Drude models [12], to methodically investigate AZO films doped with various amounts of Al. A comparison of the conductive properties, obtained from Hall effect measurements and from spectroscopic ellipsometry measurements in the near-IR range, reveals that the motions of the free carriers driven by the constant electric Lorentz force and by the alternate electromagnetic wave scatters differently on the AZO film [21,22].

\section{Materials and Methods}

\subsection{Sample Preparation}

In our previously published articles, the apparatus for the ion-beam sputtering system included an ion source, as shown in Figure 1. Both high-purity zinc and aluminum metal targets were mounted side by side on a water-cooled copper block. By adjusting the distance $H$ between the $\mathrm{Zn}$ target and the center of the ion beam, the ratio of the Al sputtering area to the total sputtering area (marked with a red ellipse, as shown in Figure 1) could be changed to control the amount of Al dopant in the deposited AZO film on the B270 glass and Si wafer substrates. The transmittance in the UV/visible/near-IR regions, crystalline structures, surface roughness, surface morphology and cross-section structure, atomic percentages (at.\%), electrical resistivity $\left(\rho_{\text {Hall }}\right)$, free electron carrier concentration $\left(N_{\text {Hall }}\right)$, and mobility $\left(\mu_{\mathrm{Hall}}\right)$ of the films were reviewed from our previous studies [15-19].

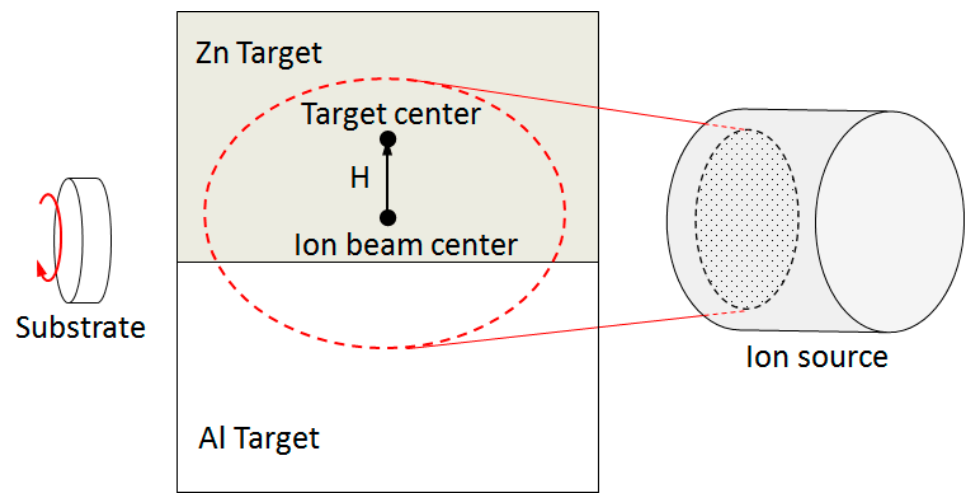

Figure 1. Schematic of the ion-beam co-sputtering system used in this study.

\subsection{Optical Models}

In this study, the AZO films were characterized via spectroscopic ellipsometry with amplitude ratios $\Psi$ and phase differences $\Delta$ at three incident angles, $55^{\circ}, 60^{\circ}$, and $65^{\circ}$, in the wavelength region of 350-1000 nm using a VASE ellipsometer M-2000U (J. A. Woollam Co., Inc., Lincoln, NE, USA). We used the ellipsometer's computer program to fit the measured data with a three-layer optical model comprised of an effective medium approximation (EMA) layer consisting of voids and AZO bulk, an AZO layer on the silicon wafer substrate, and a top layer with surface roughness determined by a Dimension 3100 atomic force microscope (AFM; Veeco Instruments Inc., Plainview, NY, USA), as shown in Figure $2[18,23]$. 


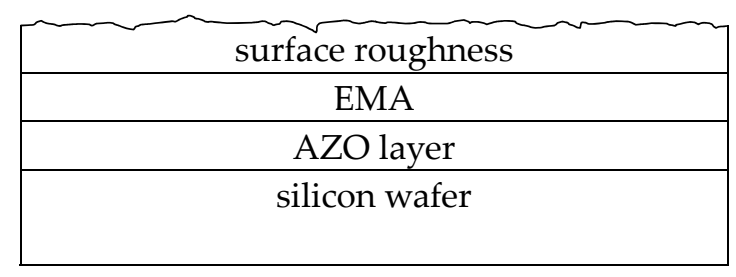

Figure 2. Al-doped $\mathrm{ZnO}$ (AZO) layer ellipsometry model using two Lorentz oscillators. The surface roughness is simulated using an effective medium approximation (EMA) layer consisting of the transition layer and voids.

The transition layer had a complex dielectric function $\widetilde{\varepsilon}(\omega)$ expressed using two Lorentz oscillator models in a frequency $(\omega)$ form as follows [24,25]:

$$
\widetilde{\varepsilon}(\omega)=\varepsilon_{\infty}+\sum_{j=1}^{2} \frac{f_{j} \omega_{j}^{2}}{\omega_{0 j}^{2}-\omega^{2}+i \gamma_{j} \omega}
$$

The $\varepsilon_{\infty}$ was the background permittivity for a high frequency near infinity. The $\omega_{0 j}, f_{j}$, and $\gamma_{j}$ were the resonance frequency, strength factor, and damping constant for the $j$ th oscillator, respectively. The model was expressed in an energy form as shown below [20,24]:

$$
\widetilde{\varepsilon}(E)=\varepsilon_{\infty}+\sum_{j=1}^{2} \frac{A_{j}}{E_{0 j}^{2}-E^{2}-i B_{j} E}
$$

where $A_{j}, B_{j}$, and $E_{0 j}$ were the amplitude, the broadening, and the center energy of the $j$ th oscillator, respectively. The AZO films showed the optical absorption in the UV range due to the electron interband transition, and also the optical reflection caused by the free-carrier vibration in the near-IR range. Equations (1) and (2) were then rewritten to a Lorentz model and a Drude model whose $E_{0 j}$ in the near-IR range approached zero, as follows:

$$
\widetilde{\varepsilon}(E)=\varepsilon_{\infty}-\frac{\omega_{\mathrm{p}}^{2}}{\omega^{2}+i \omega_{\tau} \omega}+\frac{\omega_{\mathrm{L}}^{2}}{\omega_{\mathrm{L}}^{2}-\omega^{2}-i \gamma_{\mathrm{L}} \omega}
$$

and,

$$
\widetilde{\varepsilon}(E)=\varepsilon_{\infty}-\frac{A_{\mathrm{D}}}{E^{2}+i B_{\mathrm{D}} E}+\frac{A_{\mathrm{L}}}{E_{\mathrm{L}}^{2}-E^{2}-i B_{\mathrm{L}} E}
$$

Comparing Equation (3) and Equation (4), the Drude-model amplitude $A_{D}$ and broadening parameter $B_{\mathrm{D}}$ were, respectively, related to the plasma frequency $\omega_{\mathrm{p}}$ and the damping frequency $\omega_{\tau}$ using:

$$
A_{\mathrm{D}}=\hbar^{2} \omega_{\mathrm{p}}^{2}, B_{\mathrm{D}}=\hbar \omega_{\tau}
$$

where $\hbar$ is the Planck constant $h$ divided by $2 \pi$ (i.e., $h / 2 \pi=6.585450 \times 10^{-16} \mathrm{eV} \mathrm{s}$ ). Moreover, the optical carrier concentration $\left(N_{\text {opt }}\right)$ and optical carrier mobility $\left(\mu_{\text {opt }}\right)$ were functions of $\omega_{\mathrm{p}}$ and $\omega_{\tau}$. Equation (5) can be rewritten as:

$$
N_{\mathrm{opt}}=\left(\varepsilon_{0} \varepsilon_{\infty} m^{*} / e^{2}\right) \omega_{\mathrm{p}}^{2}=\left(\varepsilon_{0} \varepsilon_{\infty} m^{*} / \hbar^{2} e^{2}\right) A_{\mathrm{D}}
$$

and,

$$
\mu_{\mathrm{opt}}=\left(e / m^{*}\right) / \omega_{\tau}=\left(\hbar e / m^{*}\right) / B_{\mathrm{D}}
$$

where $e$ is the electron charge $1.602 \times 10^{-19} \mathrm{C}, \varepsilon_{0}$ is the permittivity $8.85 \times 10^{-12} \mathrm{~F} / \mathrm{M}$ in free space, and $m^{*}=0.28 m_{\mathrm{e}}$ is the effective mass $\left(m_{\mathrm{e}}\right.$ : electron mass $\left.9.10 \times 10^{-31} \mathrm{~kg}\right)[25,26]$. Meanwhile, for the Lorentz oscillators, the $\omega_{\mathrm{L}}$ and $\gamma_{\mathrm{L}}$ of Equation (3) are the resonance frequency and damping constant, 
respectively; $A_{\mathrm{L}}$ and $B_{\mathrm{L}}$ are the amplitude and broadening, respectively; and $E_{\mathrm{L}}$ is the center energy. The electrical resistivity $\rho_{\mathrm{opt}}$ is proportional to the ratio of the damping frequency to the square of the plasma frequency (i.e., $\rho_{\mathrm{opt}} \approx \omega_{\tau} / \omega_{\mathrm{p}}{ }^{2}$ ). Thus, $\rho_{\mathrm{opt}}$ is expressed and rewritten based on Equations (5)-(7) as [27,28]:

$$
\rho_{\mathrm{opt}}=\left(\hbar / \varepsilon_{0} \varepsilon_{\infty}\right) B_{\mathrm{D}} / A_{\mathrm{D}}=1 /\left(e N_{\mathrm{opt}} \mu_{\mathrm{opt}}\right)
$$

which is proportional to the reciprocals of $N_{\text {opt }}$ and $\mu_{\text {opt }}[27,29]$. We compared the $\rho_{\text {opt }}, N_{\text {opt }}$, and $\mu_{\text {opt }}$ values with the electrical resistivity $\rho_{\text {Hall }}$, carrier concentration $N_{\text {Hall }}$, and mobility $\mu_{\text {Hall }}$ of the Hall-effect measurements.

\section{Results and Discussion}

\subsection{Deposition of Intrinsic $\mathrm{ZnO}$ Film}

In our previous studies, we deposited intrinsic $\mathrm{ZnO}$ ( $\mathrm{ZnO}-i)$ films with thicknesses of $92.6 \pm 28.1 \mathrm{~nm}$ using ion-beam sputter deposition (IBSD) at room temperature under different oxygen partial pressure $\left(P_{\mathrm{O}_{2}}\right)$. The deposition rate reduced with increasing $P_{\mathrm{O}_{2}}$ as a result of $\mathrm{ZnO}$ oxide formation on the surface of the metallic $\mathrm{Zn}$ target; the optimal $P_{\mathrm{O}_{2}}$ was found when the deposition rate no longer showed a clear decrease [30]. An optimal oxygen-deficient state was exhibited in the film deposited at $P_{\mathrm{O}_{2}}=0.12$ mTorr [15]. Moreover, the ZnO-i films deposited at $P_{\mathrm{O}_{2}}>0.1$ had an average transmittance superior to $80 \%$ in the visible and near-IR regions, with a transmittance close to zero in the UV range, as shown in Figure 3.

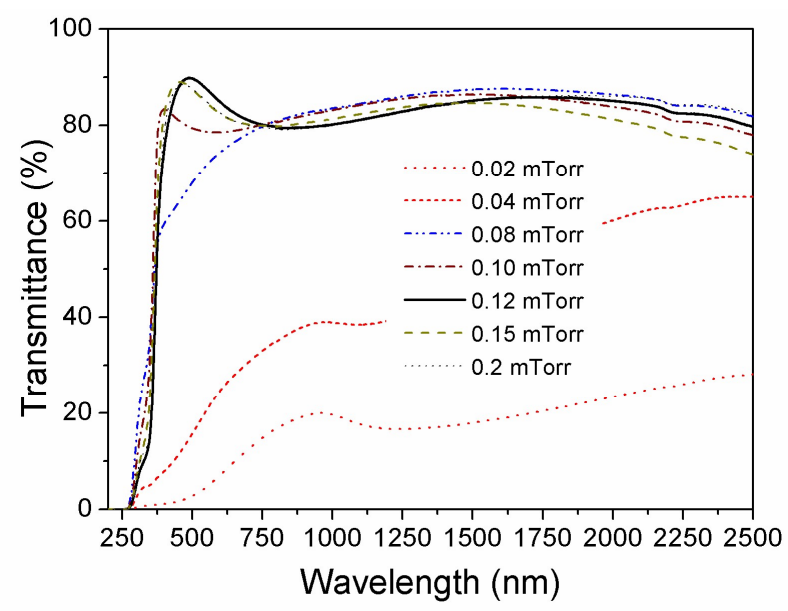

Figure 3. Transmittances of pure $\mathrm{ZnO}$ films deposited using ion-beam sputter deposition (IBSD) at various oxygen partial pressures $\left(P_{\mathrm{O}_{2}}\right)$.

The average energy band gap $\left(E_{\mathrm{g}}\right)$ of the $\mathrm{ZnO}-i$ films, determined by applying the Tauc model in our previous study, is only $3.35 \pm 0.045 \mathrm{eV}$ [16]. The small $0.045-\mathrm{eV}$ value appeared to be due to the insignificant blueshift in the optical band gap.

The ZnO- $i$ film's structures changed from the amorphous to the crystalline state, illustrating only the fitted X-ray diffraction (XRD) peak (002). In Figure $4 \mathrm{a}$, the $2 \theta$ value (where $\theta$ is the Bragg diffraction angle) changes from $33.96^{\circ}$ to $34.11^{\circ}$ with increasing $P_{\mathrm{O}_{2}}$ when $P_{\mathrm{O}_{2}}>0.1 \mathrm{mTorr}$, owing to the self-assembly property of the $\mathrm{ZnO}-i$ film $[15,31]$. The grain size mostly decreased with increasing $P_{\mathrm{O}_{2}}>0.1$ mTorr. The small variation of the $\mathrm{ZnO}-i$ grains is denoted by the gray triangles $(\Delta)$ in Figure 5 . The film was optimally deposited at $P_{\mathrm{O}_{2}}=0.12 \mathrm{mTorr}$ and had the highest peak intensity and $\theta$ value. This film had a larger grain size of $17.9 \mathrm{~nm}$, as evaluated by Scherrer's formula $s=0.9 \lambda / B \cos \theta$, where $\lambda$ is the $X$-ray wavelength of $0.154 \mathrm{~nm}, s$ is the grain size, and $B$ is the full width at half maximum (FWHM) of the XRD peak. 


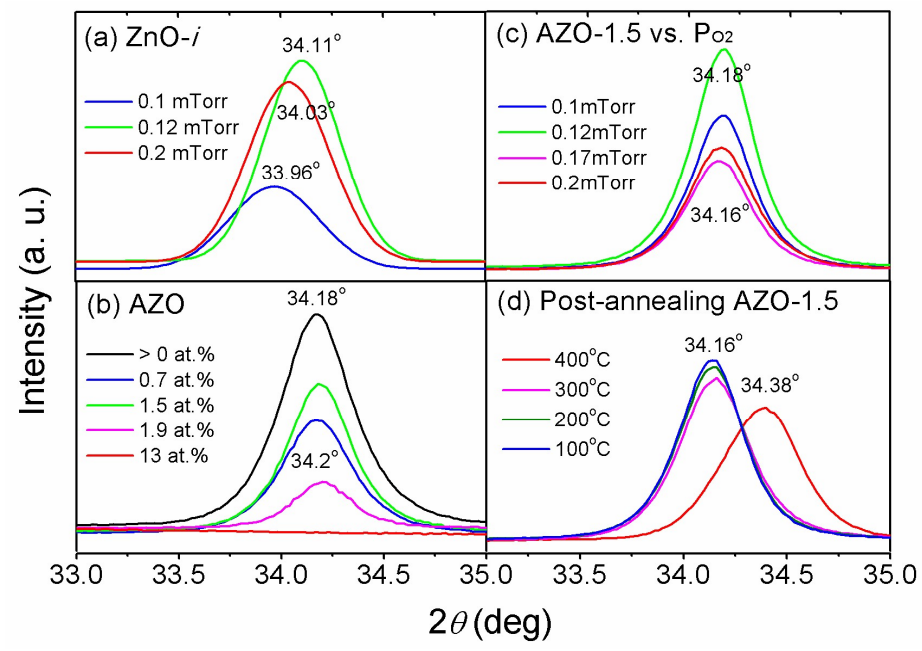

Figure 4. XRD patterns obtained for (a) ZnO-i films deposited at various $P_{\mathrm{O}_{2}}$, (b) AZO films doped at various $\mathrm{Al} \%$, (c) AZO-1.5 films deposited at various $P_{\mathrm{O}_{2}}$, and (d) AZO-1.5 films at various post-annealing temperatures in air.
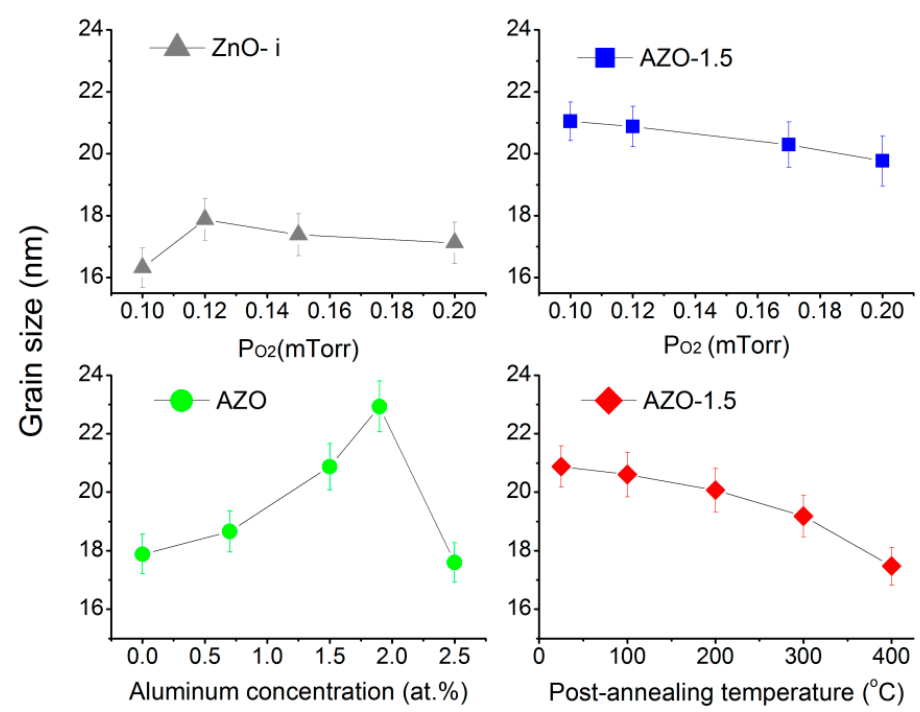

Figure 5. XRD grain sizes of $\mathrm{ZnO}-i$ films deposited at various $P_{\mathrm{O}_{2}}$ (gray triangles $\triangle$ ), $\mathrm{AZO}$ films at various $P_{\mathrm{O}_{2}}$ (blue squares $\bullet$ ), AZO films doped at various $\mathrm{Al}$ concentrations (green circles $\bullet$ ), and AZO films at various post-annealing temperatures in air (red diamonds $\diamond$ ).

Otherwise, the average resistivity of the $\mathrm{ZnO}-i$ films was $6.3 \pm 4.7 \mathrm{~m} \Omega \mathrm{cm}$. The $\mathrm{ZnO}-i$ films deposited at $P_{\mathrm{O}_{2}}=0.12$ mTorr had a minimum resistivity of $2.40 \pm 0.12 \mathrm{~m} \Omega \mathrm{cm}$ [15]. However, the resistivity of $\mathrm{ZnO}-i$ was still too large to apply to a CTO film for commercial use. The above-mentioned insignificant blueshift in the UV region and the high transmittance in the near-IR region were due to the low number of free carriers in the film.

\subsection{Deposition of AZO Films}

The $\mathrm{ZnO}-i$ films exhibited n-type conductivity due to the intrinsic donors, oxygen vacancies, and/or Zn interstitials. They lacked thermal stability and had larger resistivity, although their crystallinities were improved and their resistivities were degraded by the post-annealing at high temperatures [32]. A method of extrinsically doping group III elements, such as $\mathrm{Al}, \mathrm{Ga}$, and In, which substitute the $\mathrm{Zn}$ sites, was introduced for the growth of n-type $\mathrm{ZnO}$ films to reduce the resistivity and improve the thermal stability of CTO films [33]. 
The $\mathrm{Al}$ dopants reacted more efficiently with oxygen compared to the $\mathrm{Zn}$ atoms during the growth or post-growth annealing, because the Gibbs free energy of $-350.5 \mathrm{~kJ} / \mathrm{mol}$ of the $\mathrm{ZnO}$ formation was larger than the $-1582.3 \mathrm{~kJ} / \mathrm{mol}$ of the $\mathrm{Al}_{2} \mathrm{O}_{3}$ formation [34]. The $\mathrm{Al}$ atoms substituted the $\mathrm{Zn}$ sites and became donors. The oxide, $\mathrm{AlO}_{x} / \mathrm{Al}_{2} \mathrm{O}_{3}$, inhibited the defects to affect the electrical and optical properties. Therefore, we deposited $\mathrm{ZnO}$ with different $\mathrm{Al}$ dopant concentrations ( $\mathrm{Al} \%$ ) by using well-controlled ion-beam co-sputtering at different $P_{\mathrm{O}_{2}}$ and post-annealed the samples at different ambient temperatures for two hours.

Table 1 lists different $\mathrm{Al} \%$ values for different $\mathrm{H}$ values for the sputtered areas of the $\mathrm{Al}$ target. AZO-0 had little $\mathrm{Al}$ content because the ion beam essentially individually sputtered the zinc target at $H=16.5 \mathrm{~mm}$. The AZO film was prepared with an approximately $220 \mathrm{~nm}$ thickness at different $H$ values. Although the ion beam equally co-sputtered the $\mathrm{Al}$ and $\mathrm{Zn}$ targets at $H=50 \mathrm{~mm}$, the AZO-13 film was only doped with 13 at.\% $\mathrm{Al}$ concentration, since the sputtering rate of the $\mathrm{Al}$ metal was smaller than that of the $\mathrm{Zn}$ metal. The deposited film belongs to an amorphous film rather than a CTO film when the atomic percentage is greater than 13 at.\%. We discuss successive alterations of the structural, electrical, and optical properties of the AZO films in the following section.

Table 1. The as-deposited AZO films deposited at $P_{\mathrm{O}_{2}}=0.12 \mathrm{mTorr}$ and their respective values for $H$, $\mathrm{Al}$ concentration, thickness, and surface roughness.

\begin{tabular}{ccccc}
\hline Sample & $\boldsymbol{H}^{*}(\mathbf{m m})$ & Al Dopant (at. \%) & Thickness (nm) & $\begin{array}{c}\text { Surface } \\
\text { Roughness (nm) }\end{array}$ \\
\hline AZO-0 & $13.5 \pm 3.1$ & $0+0.1$ & $238 \pm 11$ & $2.68 \pm 0.21$ \\
AZO-0.7 & $22.0 \pm 2.9$ & $0.69 \pm 0.1$ & $218 \pm 10$ & $2.54 \pm 0.18$ \\
AZO-1.5 & $28.5 \pm 2.5$ & $1.5 \pm 0.1$ & $221 \pm 9$ & $2.48 \pm 0.15$ \\
AZO-1.9 & $35.0 \pm 2.5$ & $1.9 \pm 0.2$ & $245 \pm 11$ & $1.73 \pm 0.14$ \\
AZO-2.5 & $38.0 \pm 2.3$ & $2.5 \pm 0.2$ & $220 \pm 15$ & $1.70 \pm 0.15$ \\
AZO-7.3 & $48.0 \pm 3.1$ & $7.3 \pm 0.2$ & $231 \pm 14$ & $1.12 \pm 0.16$ \\
AZO-13 & $50.0 \pm 3.5$ & $13.0 \pm 0.2$ & $216 \pm 11$ & $1.02 \pm 0.15$ \\
\hline
\end{tabular}

*: $H$ denotes the distance between the centers of the $\mathrm{Zn}$ target and of the ion beam, as shown in Figure 1. The position error mainly comes from the maintenance process of the ion source.

\subsection{Structural Properties of the AZO Film}

When $\mathrm{Al}^{3+}$ ion with a radius in the region of 53-67.5 pm replaced $\mathrm{Zn}^{2+}$ ion with a larger radius in the region of 74-104 pm, the diffraction angle $\theta$ became larger and the $d$-spacing between (002) atomic planes became shorter, owing to Bragg's diffraction condition, $d=\lambda / 2 \sin \theta$. A suitable $\mathrm{Al} \%$ was effective for releasing residual compressive stress in the plane of the AZO film, which is considered to be an effective way to improve film stability and increase grain size [19].

The AZO-0 XRD intensity was larger than that of the other AZO films, although the Al dopant inhibited the XRD intensity, as shown in Figure $4 \mathrm{~b}$. The crystal quality of the AZO films was degraded but they still exhibited a single-phase wurtzite $\mathrm{ZnO}$ structure. With increasing $\mathrm{Al} \%$, from $>0$ at.\% to $\sim 13$ at. $\%$, the value of $2 \theta$ shifting from $34.18^{\circ}$ for the AZO-0 film to $34.2^{\circ}$ for the AZO- 13 film demonstrates that the $\mathrm{Al}-\mathrm{O}$ bonds replaced the partial $\mathrm{Zn}-\mathrm{O}$ bonds. As shown in Figure 5 with green circles $(\bullet)$ and in Table 1, the grain size apparently increased from 18.3, 18.7 to $22.9 \mathrm{~nm}$, but the root-mean-square (RMS) value for the surface roughness reduced from 2.68, 2.54 to $2.48 \mathrm{~nm}$ with increasing $\mathrm{Al} \%$. When $\mathrm{Al} \%$ increased to $2.5 \mathrm{at} . \%$, the grain size decreased to $17.6 \mathrm{~nm}$. Furthermore, the excess $\mathrm{Al} \%$ eliminated the poly-crystalline XRD signal, resulting in a reduction in the RMS value to $1.02 \mathrm{~nm}$ for the AZO-13 film, as shown in Table 1. The pillar-like cross-section and the surface morphologies of the AZO samples, such as for AZO-0 to AZO-1.9, in the SEM images in Figure 6a,b illustrate the forms of the polycrystalline structure. The destruction of the amorphous structure of AZO-13 can be seen in Figure $6 c, d$. 

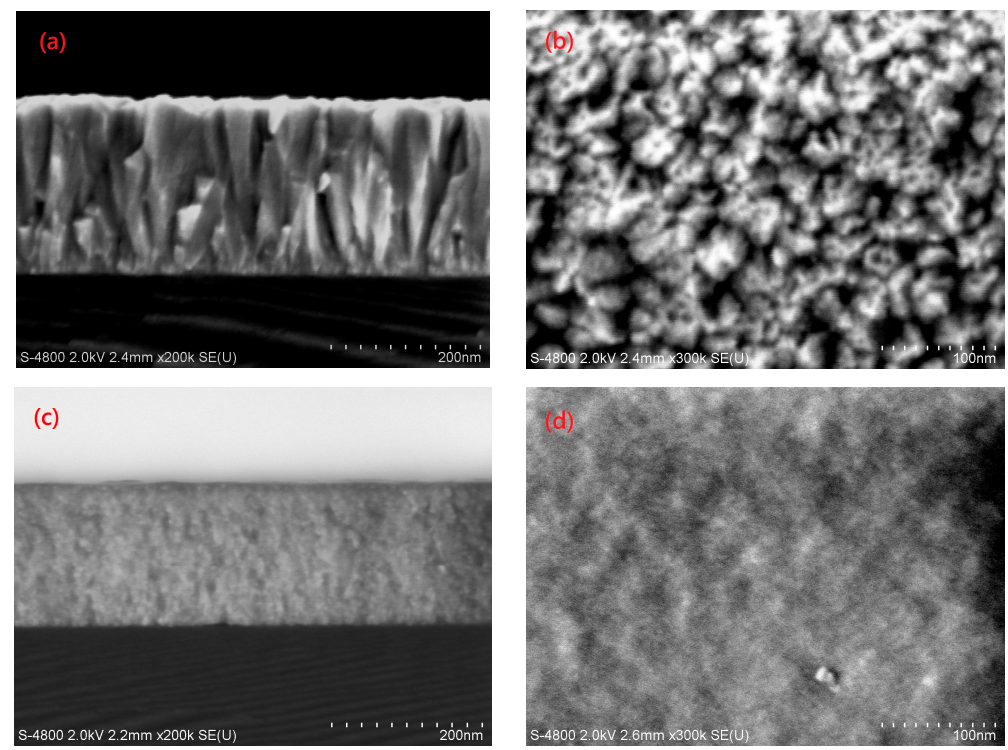

Figure 6. SEM morphologies of the (a) surface and (b) cross-section of the AZO-1.5 film; SEM morphologies of the (c) surface and (d) cross-section of the AZO-13 film.

The XRD peaks of the AZO-1.5 films deposited at different $P_{\mathrm{O}_{2}}$ values from 0.1 to 0.2 mTorr showed little change at approximately $34.18^{\circ}$, as shown in Figure $4 \mathrm{c}$. The films deposited at $0.12 \mathrm{mTorr}$ had the best poly-crystalline structure, owing to the high peak and the large grain of $20.9 \mathrm{~nm}$, denoted with blue squares (-) in Figure 5. Moreover, the grain sizes, denoted with red diamonds $(\diamond)$ in Figure 5, were further reduced with increasing post-annealing ambient temperature, owing to the enhanced oxidation process.

The grain size affected the conductivity of the AZO film, as a result of the free-carrier scattering in the film. The larger the grain size, the smaller the resistivity. By controlling the deposition parameters, larger grain sizes could be grown in the AZO film. Although the grain size of the AZO-1.5 film was smaller than that of the AZO-1.9 film, the AZO-1.5 film had the optimal Al\% by producing more free-carrier mobility to decrease the resistivity as discussed following section.

\subsection{Electrical Properties}

The conductive mechanism of the $\mathrm{ZnO}-i$ and $\mathrm{AZO}$ films was dominated by electrons produced from donor sites associated with oxygen vacancies, zinc interstitial sites, and antisite oxide in the film. In our studies, the n-type electron particles, obtained from the Hall-effect measurements, were the principal free carriers scattered in the polycrystalline films [19]. The relative concentration was influenced by the $P_{\mathrm{O}_{2}}, \mathrm{Al} \%$, and post-annealing temperatures in air, as shown in Figure 7.

However, the $\mathrm{ZnO}-i$ films deposited at various $P_{\mathrm{O}_{2}}$ had small n-type carrier concentrations, $N_{\text {Hall }}$ $<0.05 \times 10^{20} \mathrm{~cm}^{-3}$, as shown by the gray triangles $(\Delta)$ in Figure $7 \mathrm{a}$. Although the $N_{\text {Hall }}$ value decreased at $P_{\mathrm{O}_{2}}=0.12 \mathrm{mTorr}$, the grain size and mobility values became significantly larger, as shown by the gray triangles $(\triangle)$ in Figure 8a. This improvement resulted from the formation of the $\mathrm{ZnO}$ crystalline structures deposited at this $P_{\mathrm{O}_{2}}$. Thus, the AZO-1.5 film's $N_{\text {Hall }}$ sharply increased to $14.36 \times 10^{20} \mathrm{~cm}^{-3}$ and decreased in overall $\mathrm{Al} \%$ to approximately 7.3 at.\%, as shown by the green circles (॰) in Figure $7 \mathrm{a}$. The $N_{\text {Hall }}$ values of the post-annealed films at 100 or $200{ }^{\circ} \mathrm{C}$ somewhat increased to $15.6 \times 10^{20} \mathrm{~cm}^{-3}$, as shown by the red diamonds $(\diamond)$ in Figure $7 \mathrm{~b}$ illustrating the AZO-1.5 film's thermal stability. The AZO film became fully oxidized at post-annealing temperatures larger than $300^{\circ} \mathrm{C}$. In addition, the $N_{\text {Hall }}$ value of the film deposited at $P_{\mathrm{O}_{2}}=0.12$ mTorr was somewhat larger than that of those deposited at other $P_{\mathrm{O}_{2}}$ values from 0.1 to 0.2 mTorr, as shown by the blue squares ( $\left.\mathbf{(}\right)$ in Figure $7 \mathrm{~b}$. 


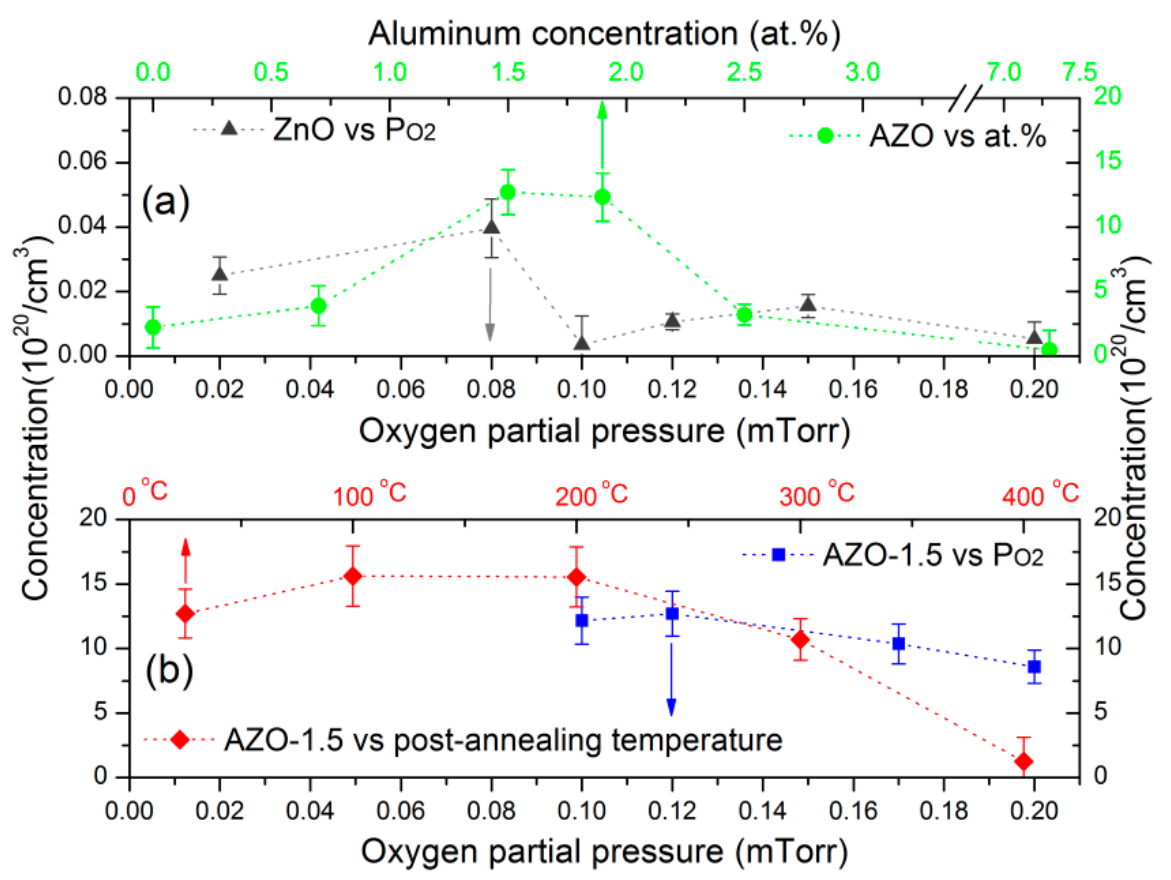

Figure 7. (a) Free-carrier concentrations of $\mathrm{ZnO}$ films prepared at different oxygen pressures and doped Al concentrations; (b) Free-carrier concentrations of AZO-1.5 films prepared at different oxygen pressures and post-annealing at different temperatures in air.

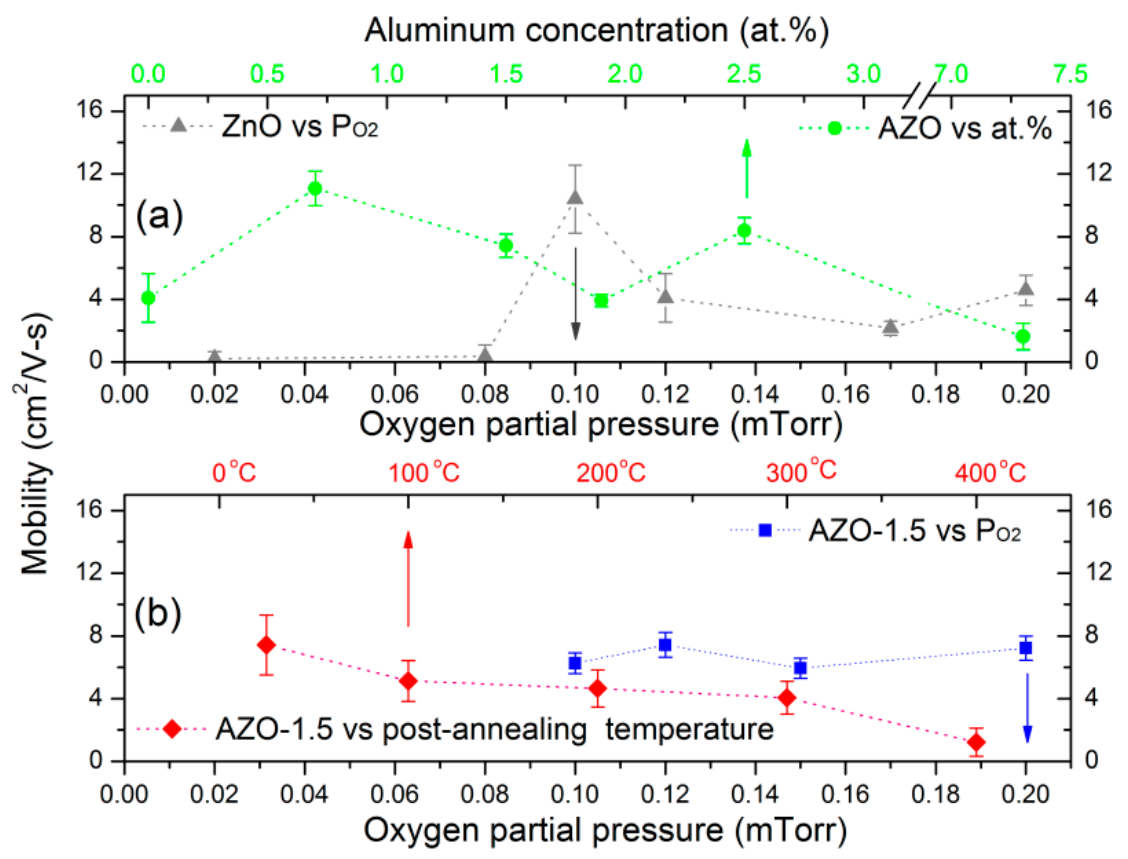

Figure 8. (a) Free-carrier mobilities of $\mathrm{ZnO}$ films prepared at different oxygen pressures and doped $\mathrm{Al}$ concentrations; (b) Free-carrier mobilities of AZO-1.5 films prepared at different oxygen pressures and post-annealing at different temperatures in air.

The free-carrier mobility was another important electrical issue for the CTO films. The ZnO- $i$ mobility value increased at $P_{\mathrm{O}_{2}}=0.1$ mTorr, then decreased with increasing $P_{\mathrm{O}_{2}}$, as shown by the gray triangles $(\Delta)$ in Figure $8 \mathrm{a}$, because the sub-oxide $\mathrm{ZnO}$ had more deficiencies than the full-oxide $\mathrm{ZnO}$ in the film. However, the selected $P_{\mathrm{O}_{2}}$ of 0.12 mTorr resulted in AZO film depositions that had 
larger grains as shown by the blue squares ( $\bullet$ ) in Figure 5, thus improving the mobility by reducing grain boundary scattering and increasing intra-grain scattering. Otherwise, increasing the $P_{\mathrm{O}_{2}}$ or the post-annealing temperature did not significantly improve the mobility, as shown by the blue squares (-) and red diamonds $(\diamond)$ in Figure 8 b, respectively. The $\mathrm{Al} \%$, shown by the green circles (॰) in Figure $8 \mathrm{a}$, further altered the mobility of the free carriers, whose modification during the Hall measurements was relative to the mean free path $L$ calculated using the formula [35]:

$$
L=\left(3 \pi^{2}\right)^{1 / 3}\left(h e^{-2}\right) \rho_{\text {Hall }}{ }^{-1} N_{\text {Hall }}{ }^{-2 / 3}
$$

The average $L$ value of our AZO samples was $8.6 \pm 2.1 \mathrm{~nm}$ [16]. However, the $L$ values under the near-IR irradiation of a rapidly oscillating electric field in a small nanometer range were much smaller than the typical grain size [36]. Steinhauser et al. [28] studied the continuous transformation of grain boundary scattering to intra-grain scattering of boron-doped $\mathrm{ZnO}$ thin films, whose $L$ values reduced from $3 \times 10^{19}$ to $2 \times 10^{20} \mathrm{~cm}^{-3}$ with increasing $N_{\text {Hall }}$. The intra-grain scattering mechanism occurred mainly when the $L$ value was relatively shorter than the grain size of $600 \mathrm{~nm}$, regardless of the grain boundary scattering, because the free carriers were transported easily inside the crystalline film [28]. However, in our research, an average grain size of only $\sim 20 \mathrm{~nm}$, much smaller than $600 \mathrm{~nm}$, was a crucial factor for determining the scattering mechanism at $N_{\text {Hall }}>2 \times 10^{20} \mathrm{~cm}^{-3}$. This disparity will be discussed again in Section 3.6.

The ZnO- $i$ film's resistivity varied with $P_{\mathrm{O}_{2}}$, as shown by the gray triangles $(\Delta)$ in Figure 9. The ZnO-i film deposited at $P_{\mathrm{O}_{2}}=0.12$ mTorr had the optimal smallest resistivity. Doping $\mathrm{Al}$ in the $\mathrm{ZnO}$ film was a good method to decrease the resistivity, $\rho_{\text {Hall }}$, which initially decreased but then increased with increasing $\mathrm{Al} \%$. The AZO-1.5 film resistivity was the smallest, although its $N_{\text {Hall }}$ was not the highest value, owing to the resistivity, in accordance with $\rho_{\text {Hall }}=1 /\left(N_{\text {Hall }} \mu_{\text {Hall }} e\right)$ [27], which changed very little at various $P_{\mathrm{O}_{2}}$ or at post-annealing temperatures of $100{ }^{\circ} \mathrm{C}$ and $200{ }^{\circ} \mathrm{C}$ in air. The poor thermal stability of the resistivity for the pure $\mathrm{ZnO}-i$ was improved but also reduced by the optimal extrinsic $\mathrm{Al} \%$ of 1.5 at.\% [33]. However, the $N_{\text {Hall }}$ and $\mu_{\text {Hall }}$ decreased and the $\rho_{\text {Hall }}$ increased with temperatures of up to $300^{\circ} \mathrm{C}$, as shown by Kuprenaite et al. [37].

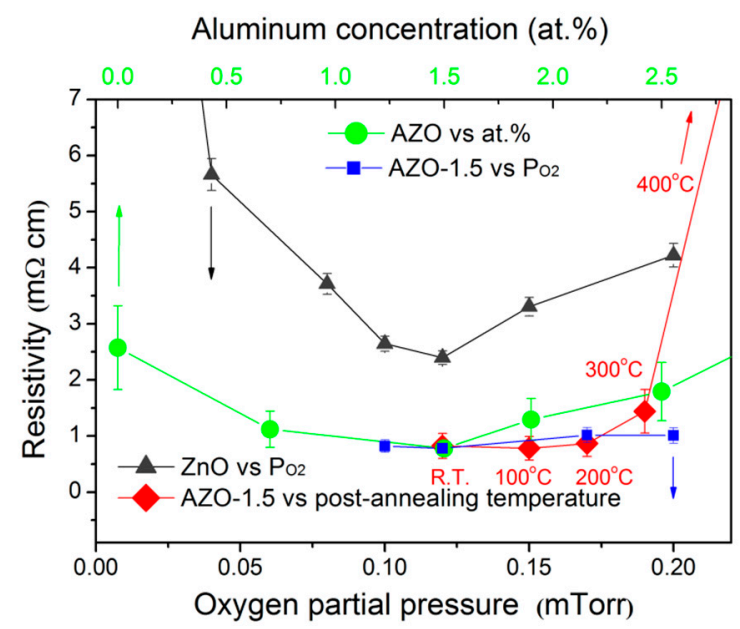

Figure 9. The resistivity of $\mathrm{ZnO}$ films deposited at various oxygen partial pressures.

\subsection{Optical Properties}

The AZO film's transmittance in the $250-2000 \mathrm{~nm}$ range is shown in Figure 10. The transmittance increases and decreases in the visible region as a result of optical interference. The average transmittance is superior to $80 \%$ in the visible range $400-700 \mathrm{~nm}$ and then decreases from 875 to $2000 \mathrm{~nm}$, where the reflectance abruptly increases after the plasma wavelength; this phenomenon is related to the optical carrier concentration $[12,28,38]$. The dopant $\mathrm{Al}$ atoms that lost their valence 
electrons tended to form $\mathrm{Al}^{3+}$ cations more readily than the substituted $\mathrm{Zn}$ atoms, which tended to form $\mathrm{Zn}^{2+}$ cations. The valence electrons increased at the substituted $\mathrm{Zn}$ sites, resulting in the increase of the carrier concentration. The AZO-1.5 film at the lowest near-IR transmittance, shown in Figure 7a, had the greater number of free carriers. In contrast, for the AZO-13 film, there was no evident wurtzite $\mathrm{ZnO}$ in the film's matrix, which contains hexagonal $\mathrm{ZnO}$ and rhombohedral $\mathrm{Al}_{2} \mathrm{O}_{3}$ structures in the heavy dopant, as found by $\mathrm{Lu}$ et al. [39]. It had a high near-IR transmittance due to the few free carriers. The AZO-7.3 film was partially composed of polycrystalline $\mathrm{ZnO}$ and $\mathrm{AlO}_{x} / \mathrm{Al}_{2} \mathrm{O}_{3}$ materials. We attribute the medium transmittance to the lower carrier concentration than that of $\mathrm{ZnO}-1.5$ in the film. Thus, the near-IR transmittance, shown in Figure 10, decreased to the lowest value for the AZO-1.5 film then increased back to the highest value for the AZO- 13 film with increasing $\mathrm{Al} \%$.

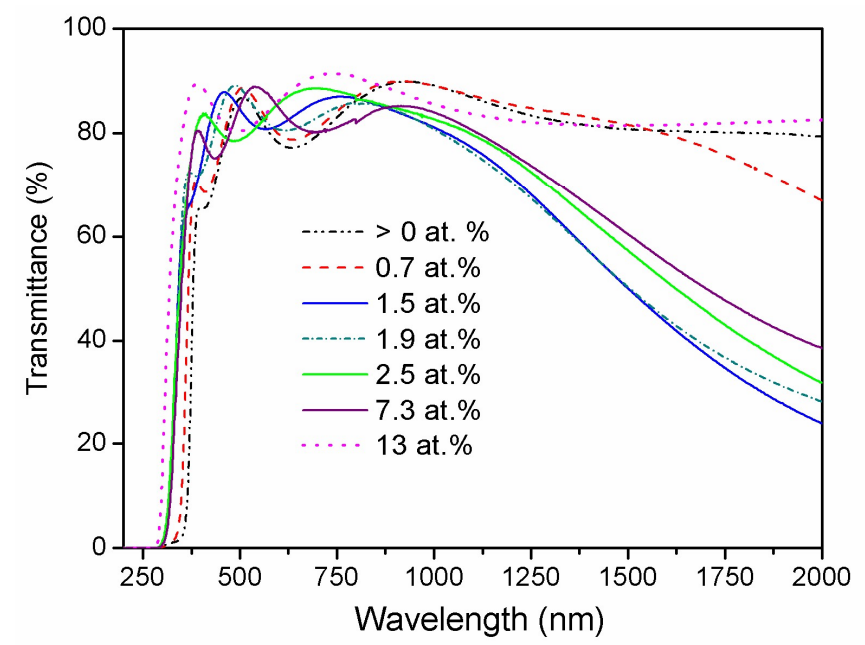

Figure 10. Transmittance spectra of AZO films doped with different concentrations of aluminum (at.\%).

The optical absorption of the AZO films was close to zero at $\sim 375 \mathrm{~nm}$ in the UV region. The $E_{\mathrm{g}}$ value, determined using the Tauc plot method, somewhat increased with increasing $\mathrm{Al} \%$. A small $E_{\mathrm{g}}$ redshift of the polycrystalline ZnO-i films deposited at $P_{\mathrm{O}_{2}}>0.08$ mTorr ranged from 3.41 to $3.31 \mathrm{eV}$, shown by the gray triangles $(\Delta)$ in Figure 11a. The redshift phenomenon was due to the ZnO-i structures changing from amorphous to polycrystalline structures $[15,40]$. In contrast, the $E_{\mathrm{g}}$ values of the AZO films for $\mathrm{Al} \% 0,0.7$, and 1.5 at. \%, with increasing $N_{\text {Hall }}$ from $2.34 \times 10^{20}, 3.9 \times 10^{20}$, and $12.7 \times 10^{20} \mathrm{~cm}^{-3}$, as shown by the green circles (•) in Figure $7 \mathrm{a}$, blueshifted from 3.3, 3.4, and $3.8 \mathrm{eV}$, as shown the green circles (๑) in Figure 11a, respectively, due to the Burstein-Moss (B-M) effect [18,41] They redshifted again for $\mathrm{Al} \%>2.5 \mathrm{at} . \%$ for smaller values of $N_{\mathrm{Hall}}$. The result agrees well with the observations from the optical and electrical measurements. Otherwise, the AZO-13 film, where the B-M effect was insignificant at $N_{\text {Hall }} \approx 0$, still had a high $E_{\mathrm{g}}$ value of $4.2 \mathrm{eV}$ because the film's material consisted of $\mathrm{Al}_{2} \mathrm{O}_{3}$ with $E_{\mathrm{g}}$ of $6.2 \mathrm{eV}$ and the amorphous $\mathrm{ZnO}$ with $E_{\mathrm{g}}$ of $3.4 \mathrm{eV}$ [40].

In this study, the optical absorption in the UV region and the higher reflectance in the near-IR region are generally described as an extended Lorentz oscillator, including a Drude model, which will be discussed in Section 3.6.

Figure $11 \mathrm{~b}$ shows that the AZO-1.5 film deposited at $P_{\mathrm{O}_{2}}=0.12 \mathrm{mTorr}$ had the largest $E_{\mathrm{g}}$ with the largest $N_{\text {Hall }}$ due to the B-M effect, as shown by the blue squares ( $\left.\mathbf{(}\right)$ in Figure 7a. The $E_{\mathrm{g}}$ did not significantly change at post-annealing temperatures in air lower than $300^{\circ} \mathrm{C}$; however, it reduced significantly at $400{ }^{\circ} \mathrm{C}$, due to an almost-full-oxidation of the film, as shown by the red diamonds $(\diamond)$ in Figure 7b. 
Figure 12 shows the $N_{\mathrm{Hall}}^{2 / 3}$ values of the all $\mathrm{ZnO}-i$ and AZO films against $E_{\mathrm{g}}$ with a linear fitting. The B-M model describes the $E_{\mathrm{g}}$ of the $\mathrm{AZO}$ films with a variation of $\Delta E^{\mathrm{BM}}$ according to the formula:

$$
E=E_{0}+\Delta E^{\mathrm{BM}}=\frac{\hbar^{2}}{2 m^{*}}\left(3 \pi^{2} N_{\mathrm{Hall}}\right)^{2 / 3}
$$

The $\Delta E^{\mathrm{BM}}$ value is the widening energy between the $E_{\mathrm{g}}$ of the AZO film and that of the AZO-0 film. The blueshift $E_{\mathrm{g}}$ resulted from the increasing $N_{\text {Hall }}$ using Al-dopants. The $\Delta E^{\mathrm{BM}}$ was directly proportional to $N_{\mathrm{Hall}}{ }^{2 / 3}$. The $E_{0}$ value, obtained by extending the fitting line to the vertical axis in Figure 12, was approximately $3.3 \mathrm{eV}$, which agreed with the AZO-0 film value estimated from the transmittance in Figure 10. However, the AZO-7.3 film (green circles, $\bullet$ ) did not lie on the fitting red line in Figure 10; we attribute this to the too low $N_{\text {Hall }}$ in the film.

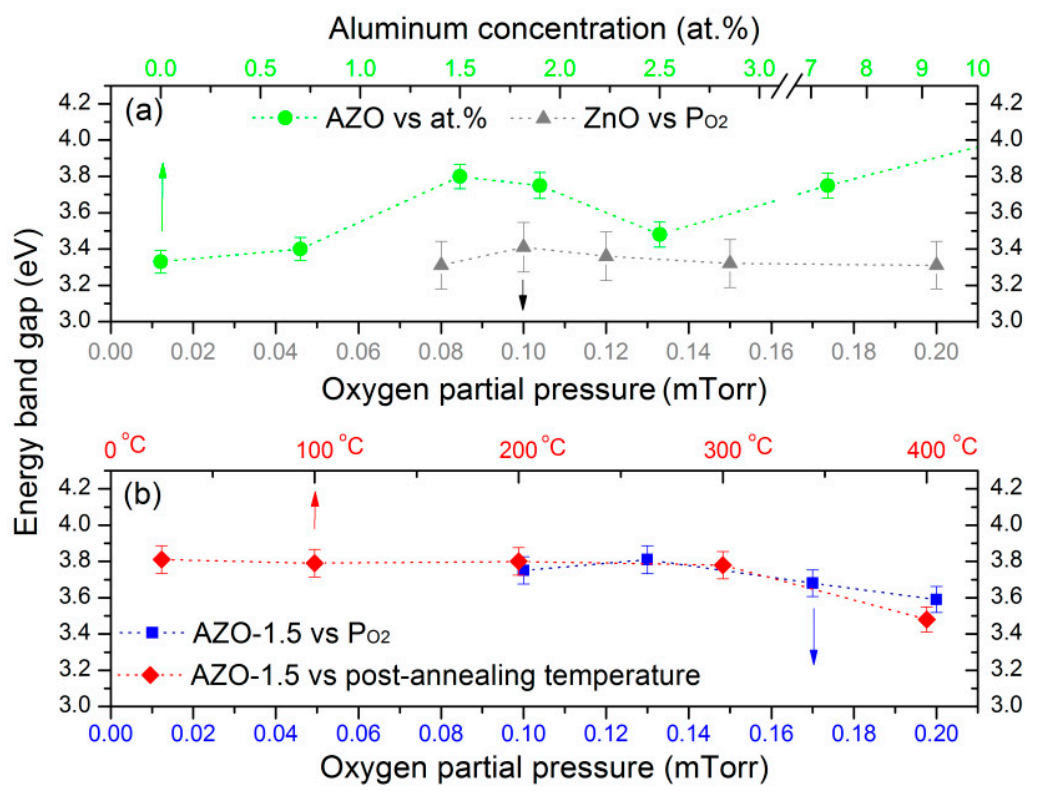

Figure 11. (a) Energy band gaps of $\mathrm{ZnO}$ films prepared at different oxygen pressures and doped $\mathrm{Al}$ concentrations; (b) Energy band gaps of AZO-1.5 films prepared at different oxygen pressures and post-annealing at different temperatures in air.

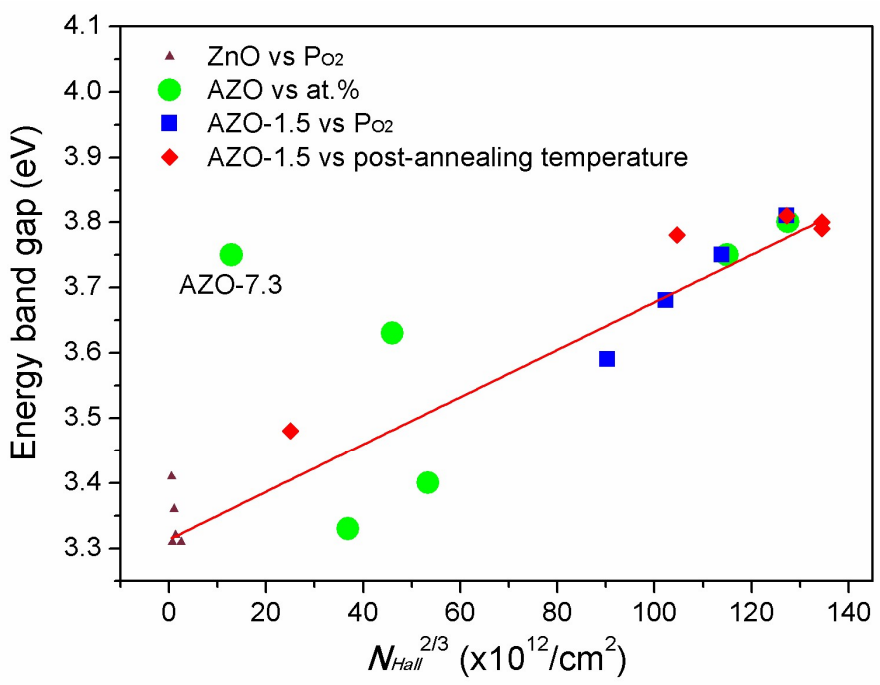

Figure 12. $N_{\text {Hall }}^{2 / 3}$ values of all $\mathrm{ZnO}-i$ and AZO films vs energy band gap. 


\subsection{Spectroscopic Ellipsometry Study}

We also illustrated the optical properties using an ellipsometry method for the low average mean square error (MSE) of $2.8 \pm 0.5$, which allowed for good simulations for the measured ellipsometry data and the fitting results of the films [24]. The average thickness was approximately $220 \mathrm{~nm}$, as listed in Table 1. We assumed the EMA layer shown in Figure 2 to contain a mixture of voids and AZO material [18]. The average rough surface measured by an AFM was approximately $2.5 \pm 0.7 \mathrm{~nm}$. The six fitted coefficients of the AZO films are listed in Table 2.

Table 2. Fitted coefficients of the two Lorentz oscillator model for the as-deposited AZO films.

\begin{tabular}{ccccccc}
\hline AZO (at.\%) & $\varepsilon_{\infty}$ & $A_{\mathbf{L}}(\mathbf{e V})^{\mathbf{2}}$ & $\boldsymbol{B}_{\mathbf{L}}(\mathbf{e V})$ & $\boldsymbol{E}_{\mathbf{L}}(\mathbf{e V})$ & $A_{\mathbf{D}}(\mathbf{e V})^{\mathbf{2}}$ & $\boldsymbol{B}_{\mathbf{D}}(\mathbf{e V})$ \\
\hline 0 & 3.42 & 5.41 & 0.203 & 3.88 & 0.52 & 0.400 \\
0.7 & 3.30 & 5.84 & 0.185 & 3.87 & 0.78 & 0.149 \\
1.5 & 2.96 & 10.3 & 0.236 & 4.27 & 1.56 & 0.107 \\
1.9 & 2.97 & 10.9 & 0.191 & 4.49 & 1.90 & 0.133 \\
2.5 & 2.8 & 11.6 & 0.210 & 4.18 & 1.33 & 0.110 \\
7.3 & 2.84 & 9.86 & 0.330 & 4.41 & 0.59 & 0.460 \\
13 & 3.11 & 2.57 & 0.001 & 4.12 & 0.21 & 0.002 \\
\hline
\end{tabular}

The $E_{\mathrm{g}}$, estimated using transmittance and shown by the white squares $(\square)$, and the gap energy $E_{\mathrm{L}}$, obtained using ellipsometry measurements and shown by the red squares $(\boldsymbol{\nabla})$, were plotted against the $\mathrm{Al} \%$ in Figure 13a. The Tauc plot is a common method for finding the $E_{\mathrm{g}}$ of crystalline semiconductors using Equation (10) for an indirect allowed transition:

$$
\alpha h v=A\left(h v-E_{\mathrm{g}}\right)^{2}
$$

where $\alpha$ is the absorption coefficient calculated using $\alpha=4 \pi k / \lambda_{\mathrm{w}}, h v$ is the photon energy, $A$ is a constant, $k$ is the extinction coefficient, and $\lambda_{\mathrm{W}}$ is the optical wavelength [42].

However, the average $E_{\mathrm{L}}$ of the polycrystalline AZO film might be located at the center of the absorption band composed of the plural absorption bands. It was larger than the $E_{\mathrm{g}}$ from the Tauc plots, as determined by D'Elia et al. [26]. The absorption edge of the crystalline semiconductor abruptly terminated in this $E_{\mathrm{g}}$ region; however, due to the multiple absorption bands, the $\mathrm{AZO}$ polycrystalline structure extended beyond this region to $E_{\mathrm{L}}$.

The $N_{\text {opt }}$ values, which was calculated using Equation (6) and the data in Table 2, and the $N_{\text {Hall }}$ values both increased then decreased with increasing $\mathrm{Al} \%$, as shown in Figure 13b. The AZO-0.7 to AZO-2.5 films had the $N_{\text {Hall }}>2 \times 10^{20} \mathrm{~cm}^{-3}$. The AZO-1.5 and AZO-1.9 films, which were approximately at the optimal doping level, had a larger difference between the $N_{\text {Hall }} \sim 1.27 \times 10^{21} \mathrm{~cm}^{-3}$ and $N_{\text {opt }} \sim 3.1 \times 10^{20} \mathrm{~cm}^{-3}$. Chinta et al. have also found the $N_{\text {Hall }}$ value from $4.86 \times 10^{19}$ to $2.99 \times 10^{20} \mathrm{~cm}^{-3}$ and the $N_{\text {opt }}$ value from $5.85 \times 10^{19}$ to $2.29 \times 10^{20} \mathrm{~cm}^{-3}$ for constant $m^{*}$ when the $\mathrm{ZnO}$ films were doped by $\mathrm{Al}$ from 0 to 10 at.\% [43].

Figure 13c shows that the two $\mu_{\mathrm{opt}}$ values calculated using Equation (7) and Table 2 were slightly lower because the free carriers scattered the charged donor impurity atoms more frequently under the electrostatic field. While the free carriers cross several grain boundaries, the scattering frequency $\omega_{\mathrm{GB}}$ is influenced by the grain boundary density [44]. By considering all scattering mechanisms, the total scattering frequency $\omega_{\text {Hall }}$ is the sum of the individual frequencies, which can be expressed by applying Matthiessen's rule:

$$
\omega_{\text {Hall }}=\omega_{\mathrm{GB}}+\omega_{\mathrm{ig}}
$$

where $\omega_{\text {ig }}$ is the sum of the individual scattering frequencies for the ionized impurity scattering, neutral impurity scattering, and lattice vibration scattering mechanisms [45]. Since the mobility was 
inversely related to the scattering frequency, as shown in Equation (7), the reciprocal addition of the mobilities represents the Hall mobility $\mu_{\text {Hall }}$ as:

$$
\mu_{\mathrm{Hall}}{ }^{-1}=\mu_{\mathrm{ig}}{ }^{-1}+\mu_{\mathrm{GB}}{ }^{-1}
$$

Although the intra-grain mobility $\mu_{\mathrm{ig}}$ was also limited by the grain size of approximately $20 \mathrm{~nm}$ in this study, the traveling distance of approximately a few nanometers, where the electron interacted with photons due to the application of a rapidly oscillating electromagnetic field, was much smaller than the grain size. The depleted scattering region at the boundaries occupied only a small volume compared with the grain size. Hence, the mobility $\mu_{\mathrm{opt}}$ was equal to the intra-grain mobility $\mu_{\mathrm{ig}}$, neglecting the grain boundary scattering [45]. To observe the discrepancy between $\mu_{\text {opt }}$ and $\mu_{\text {Hall }}$, Equation (13) is rewritten as:

$$
\mu_{\mathrm{opt}} / \mu_{\mathrm{GB}}=\left(\mu_{\mathrm{opt}}-\mu_{\mathrm{Hall}}\right) / \mu_{\mathrm{Hall}}=\mu_{\mathrm{opt}} / \mu_{\mathrm{Hall}}-1
$$

In this study, for light doping (e.g., the AZO-0 film) or over doping (e.g., the AZO-7.3 film) the $N_{\text {Hall }}<2 \times 10^{20} \mathrm{~cm}^{-3}$ and the difference between $N_{\text {opt }}$ and $N_{\text {Hall }}$ were smaller. The greatest difference in terms of the two free carrier densities occurred for the AZO-1.5 film, as shown in Figure 13b. The discrepancy between $\mu_{\text {opt }}$ and $\mu_{\text {Hall }}$ was simultaneously larger than that for the others, as shown in Figure 13c. The $\mu_{\text {opt }}$ value of $\sim 38 \mathrm{~cm}^{2} \mathrm{~V}^{-1} \mathrm{~s}^{-1}$ was much larger than the $\mu_{\text {Hall }}$ value of $\sim 8 \mathrm{~cm}^{2} \mathrm{~V}^{-1} \mathrm{~s}^{-1}$. Knoops et al. also studied the $\mu_{\text {opt }}$ and $\mu_{\text {Hall }}$ values of the deposited 150-nm-thickness AZO film were approximately 17 and $12 \mathrm{~cm}^{2} \mathrm{~V}^{-1} \mathrm{~s}^{-1}$, respectively [46]. Such inequality has also been reported for boron-doped $\mathrm{ZnO}$ film, owing to its microstructure with a poorly conducting grain boundary [28]. In this work, the grain boundary was caused by the small grain size of $\sim 20 \mathrm{~nm}$ in the AZO film. From Equation (14), the grain boundary scattering effect was predominant for the larger $\mu_{\mathrm{opt}} / \mu_{\mathrm{GB}}$ values that had the highest $\mu_{\mathrm{opt}}$ and the lower $\mu_{\text {Hall }}$, as shown in Figure 13c.

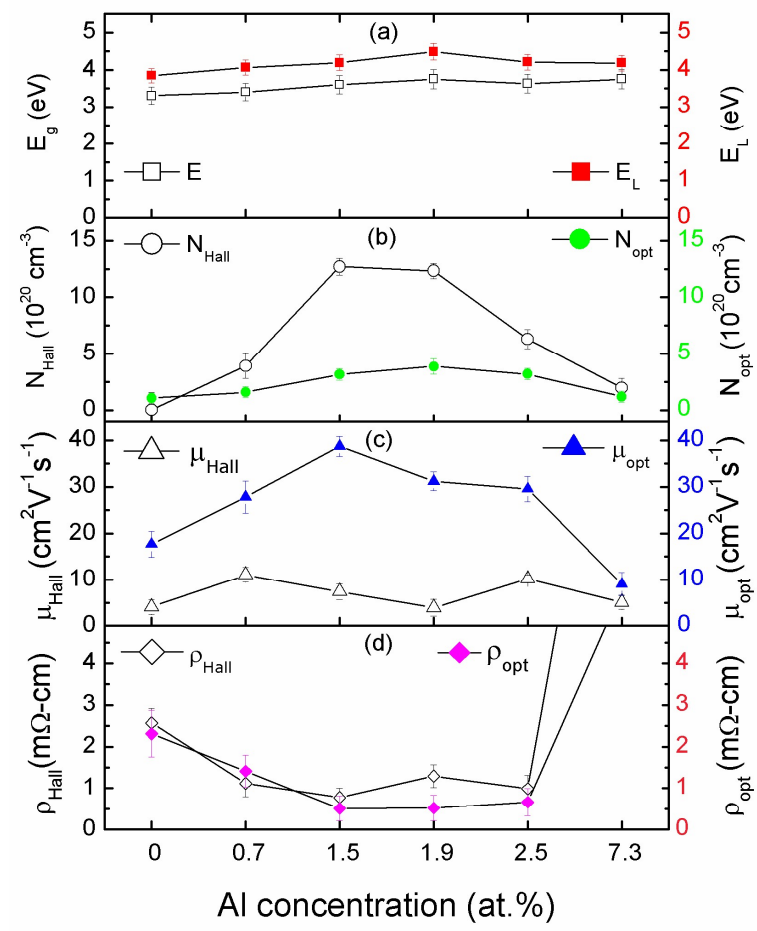

Figure 13. Comparisons of the (a) energy bandgaps, (b) free carrier densities, (c) mobilities, and (d) resistivities of the as-deposited AZO films using the data of the Hall-effect measurements and the fitted Lorentz oscillator model. 
The AZO-1.5 film also showed the lowest $\rho_{\text {opt }}$. The $\rho_{\text {opt }}$ values, which were calculated with Equation (8) and the data in Table 2, and the measured $\rho_{\text {Hall }}$ values simultaneously decreased then increased with $\mathrm{Al} \%$ increasing from $0,1.5$, to 7.3 at.\%, as shown by the pink diamonds ( $\diamond)$ in Figure $13 \mathrm{~d}$. The AZO-7.3 film had the larger resistivity, owing to the $\mathrm{Al}_{2} \mathrm{O}_{3}$ formation, as shown by the XPS spectra shown in Figure 14 for selected samples. The spectral areas for $\mathrm{AlO}_{x}$, for the $\mathrm{Al}-\mathrm{O}-\mathrm{Zn}$ bonding, and $\mathrm{Al}_{2} \mathrm{O}_{3}$, for the amorphous structure, increased with increasing $\mathrm{Al} \%$. The excess of $\mathrm{Al}$ atoms containing oxygen vacancies in the film may separate into grain boundaries and easily form a neutral $\mathrm{Al}_{2} \mathrm{O}_{3}$-based defect complex, which did not contribute to free electrons and acted as scattering centers, thereby deteriorating the electrical properties [47]. That is, the larger $\mathrm{Al}_{2} \mathrm{O}_{3}$ area for the AZO-7.3 film was observed in the $\mathrm{Al} 2 p$ XPS spectra.

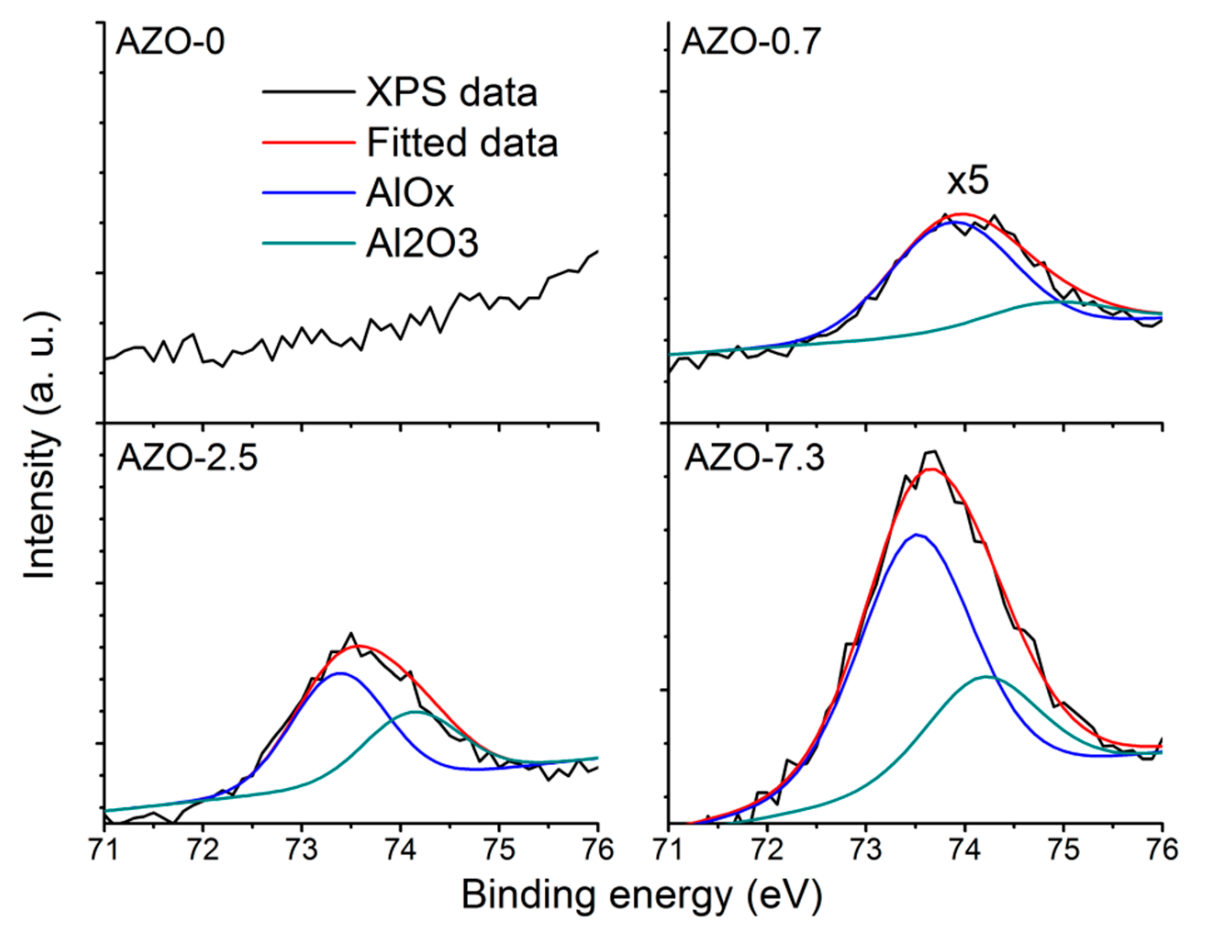

Figure 14. Al $2 p$ XPS spectra of the selected AZO samples roughly described in terms of spectral areas according to their $\mathrm{Al}$ concentrations.

The $\rho_{\text {opt }}$ and $\rho_{\text {Hall }}$ were almost identical in Figure $13 b, c$ at each $\mathrm{Al} \%$, despite the above-mentioned observations that $N_{\text {Hall }}>N_{\text {opt }}$ and $\mu_{\text {Hall }}<\mu_{\text {opt }}$, because the resistivity was mainly proportional to the reciprocal products of the mobilities and the free carrier densities. Moreover, the AZO-1.5 film had the smallest resistivities of $\rho_{\mathrm{opt}}=0.51 \mathrm{~m} \Omega \mathrm{cm}$ and $\rho_{\text {Hall }}=0.78 \mathrm{~m} \Omega \mathrm{cm}$.

The optical properties of the AZO films were affected by many factors, such as the polycrystalline structure, surface morphology, optical absorption, and $\mathrm{Al} \%$. The $\mathrm{Al}$ dopant in the $\mathrm{AZO}$ film destroyed the $\mathrm{ZnO}$ wurtzite structure because the $\mathrm{Al}-\mathrm{O}$ bonds replaced the $\mathrm{Zn}-\mathrm{O}$ bonds and shrank the bond length. The higher the $\mathrm{Al} \%$, the greater the grain size for $\mathrm{Al} \%<1.9$ at. $\%$, as shown by the green circles (॰) in Figure 5. Volintiru et al. also investigated the optical properties affected by the two film's pyramid- and pillar-like growth structures. The optical interference reduced the pyramid-like structure, owing to the optical scattering on the rough surface and the large grain boundary of the film [12]. In our study, the AZO films were between pyramid- and pillar-like grains, as shown in Figure $6 \mathrm{a}, \mathrm{b}$. Grain sizes of approximately $20 \mathrm{~nm}$ were greater than those of the pillar-like structure. Moreover, ion-beam-sputtering films have a small surface roughness, low extinction coefficient, and high packing density [30,48]. Therefore, these films have less multi-reflection of light scattering between the polycrystalline boundaries. The transmittance of the apparent interference phenomenon 
varied with different wavelengths in the visible range, as shown in Figure 10. Moreover, the near-IR transmittance reduction resulted from the increase in the higher $k$-value due to the transmittance $T$ in the air, which can be expressed as [49]:

$$
T=\frac{4 n}{(1+n)^{2}+k^{2}}
$$

The $k$ values in the visible range were smaller than those in the UV range due to the optical absorption and in the near-IR range due to the high free-carrier density. Such as, the optimal doping AZO-1.5 film had the smallest transmittance in the near-IR region due to the great $k$ value. For another limitation, the heavily doping AZO-13 film had a steady high transmittance because it is almost fully oxidized. Its $k$ value was smaller in the near-IR region.

\section{Conclusions}

The $\mathrm{ZnO}$ film deposited at oxygen partial pressure $P_{\mathrm{O}_{2}}=0.12 \mathrm{mTorr}$ had the smallest resistivity, of approximately $2.5 \mathrm{~m} \Omega$. The film's resistivity was reduced and its thermal stability was improved, at post-annealing temperatures of 100 or $200{ }^{\circ} \mathrm{C}$ in air, by using ion-beam co-sputtering for two $\mathrm{Al}$ and $\mathrm{Zn}$ targets. The optimal extrinsic $\mathrm{Al}$ dopant concentration (Al\%) of 1.5 at.\% allows the Al-doped $\mathrm{ZnO}$ (AZO) film to have a high transmittance of $>80 \%$ in the visible regions, a grain size of approximately $20 \mathrm{~nm}$ with high crystalline orientation (002), and the smallest and thermally stable resistivity of $7.8 \times 10^{-4} \Omega \mathrm{cm}$.

Moreover, AZO thin films deposited with various $\mathrm{Al} \%$ values from 0 to 13 at. $\%$ were prepared. We used an ellipsometry model with two Lorentz oscillators to successfully analyze each film's electrical and optical properties. The various $N_{\text {opt }}, \mu_{\text {opt }}$, and $\rho_{\text {opt }}$ electrical properties were compared to the $N_{\text {Hall }}, \mu_{\text {Hall }}$, and $\rho_{\text {Hall }}$ values measured using the Hall effect. For the optimal AZO- $1.5 \%$ film sample, $N_{\text {opt }}=3.1 \times 10^{20} \mathrm{~cm}^{-3}<N_{\text {Hall }}=1.27 \times 10^{21} \mathrm{~cm}^{-3}$ and $\mu_{\text {opt }}=38 \mathrm{~cm}^{2} \mathrm{~V}^{-1} \mathrm{~s}^{-1}>\mu_{\text {Hall }}=$ $7.5 \mathrm{~cm}^{2} \mathrm{~V}^{-1} \mathrm{~s}^{-1}$, due to the mechanism limiting the electron mobility. This mechanism is determined by the grain boundary scattering for the smaller grain size in our study. Each film's optical properties were evaluated to obtain the optical absorption in the UV region and the low transmittance in the near-IR region.

Author Contributions: Conceptualization, J.-C.H.; Data Curation, Y.-Y.C.; Formal Analysis, J.-C.H.; Funding Acquisition, J.-C.H.; Investigation, Y.-Y.C.; Methodology, J.-C.H.; Project Administration, J.-C.H.; Resources, J.-C.H.; Software, J.-C.H. and Y.-Y.C.; Supervision, J.-C.H.; Validation, J.-C.H. and Y.-Y.C.; Visualization, J.-C.H.; Writing-Original Draft Preparation, J.-C.H.; Writing-Review \& Editing, J.-C.H.

Funding: This research was funded by the Ministry of Science and Technology of Taiwan (No. MOST 105-2221-E-030-007-MY3 and MOST 106-2112-M-030-001-MY2).

Conflicts of Interest: The authors declare no conflict of interest.

\section{References}

1. Jiang, X.; Jia, C.L.; Szyszka, B. Manufacture of specific structure of aluminum-doped zinc oxide films by patterning the substrate surface. Appl. Phys. Lett. 2002, 80, 3090. [CrossRef]

2. Kohan, A.F.; Ceder, G.; Morgan, D.; Van De Walle, C.G. First-principles study of native point defects in ZnO. Phys. Rev. B 2000, 61, 15019. [CrossRef]

3. Kayaci, F.; Vempati, S.; Donmez, I.; Biyikli, N.; Uyar, T. Role of zinc interstitials and oxygen vacancies of ZnO in photocatalysis: A bottom-up approach to control defect density. Nanoscale 2014, 6, 10224-10234. [CrossRef] [PubMed]

4. Takata, S.; Minami, T.; Nanto, H. The stability of aluminium-doped $\mathrm{ZnO}$ transparent electrodes fabricated by sputtering. Thin Solid Films 1986, 135, 183-187. [CrossRef]

5. Minami, T. New n-type transparent conducting oxides. MRS Bull. 2000, 25, 38-44. [CrossRef] 
6. T-Thienprasert, J.; Rujirawat, S.; Klysubun, W.; Duenow, J.N.; Coutts, T.J.; Zhang, S.B.; Look, D.C.; Limpijumnong, S. Compensation in Al-doped ZnO by Al-related acceptor complexes: Synchrotron X-ray absorption spectroscopy and theory. Phys. Rev. Lett. 2013, 110, 055502. [CrossRef]

7. Verma, A.; Khan, F.; Kumar, D.; Kar, M.; Chakravarty, B.C.; Singh, S.N.; Husain, M. Sol-gel derived aluminum doped zinc oxide for application as anti-reflection coating in terrestrial silicon solar cells. Thin Solid Films 2010, 518, 2649-2653. [CrossRef]

8. Budianu, E.; Purica, M.; Iacomi, F.; Baban, C.; Prepelita, P.; Manea, E. Silicon metal-semiconductor-metal photodetector with zinc oxide transparent conducting electrodes. Thin Solid Films 2008, 516, 1629-1633. [CrossRef]

9. Chiang, Y.-F.; Sung, C.-C.; Ro, R. Effects of metal buffer layer on characteristics of surface acoustic waves in $\mathrm{ZnO} / \mathrm{metal} /$ diamond structures. Appl. Phys. Lett. 2010, 96, 154104. [CrossRef]

10. Jeong, S.S.; Mittiga, A.; Salza, E.; Masci, A.; Passerini, S. Electrodeposited $\mathrm{ZnO} / \mathrm{Cu}_{2} \mathrm{O}$ heterojunction solar cells. Electrochim. Acta 2008, 53, 2226-2231. [CrossRef]

11. Yu, K.M.; Mayer, M.A.; Speaks, D.T.; He, H.; Zhao, R.; Hsu, L.; Mao, S.S.; Haller, E.E.; Walukiewicz, W. Ideal transparent conductors for full spectrum photovoltaics. J. Appl. Phys. 2012, 111, 123505. [CrossRef]

12. Volintiru, I.; Creatore, M.; Van De Sanden, M.C.M. In situ spectroscopic ellipsometry growth studies on the Al-doped $\mathrm{ZnO}$ films deposited by remote plasma-enhanced metalorganic chemical vapor deposition. J. Appl. Phys. 2008, 103, 033704. [CrossRef]

13. Lin, K.M.; Lee, Y.H.; Huang, W.Y.; Hsieh, C.T.; Hsu, C.K. Spectroscopic ellipsometry study on strain evolution of transparent conductive thin films prepared by RF sputtering method. Adv. Mater. Res. 2015, 1110, $222-225$. [CrossRef]

14. Kinsey, N.; Devault, C.; Kim, J.; Ferrera, M.; Shalaev, V.M.; Boltasseva, A. Epsilon-near-zero Al-doped ZnO for ultrafast switching at telecom wavelengths. Optica 2015, 2, 616-622. [CrossRef]

15. Hsu, J.-C.; Chiang, Y.-S. Influence of oxygen on zinc oxide films fabricated by ion-beam sputter deposition. ISRN Mater. Sci. 2013, 2013, 710798. [CrossRef]

16. Chen, Y.-Y.; Hsu, J.-C.; Wang, P.W.; Pai, Y.-W.; Wu, C.-Y.; Lin, Y.-H. Dependence of resistivity on structure and composition of AZO films fabricated by ion beam co-sputtering deposition. Appl. Surf. Sci. 2011, 257, 3446-3450. [CrossRef]

17. Chen, Y.-Y.; Hsu, J.-C.; Lee, C.-Y.; Wang, P.W. Influence of oxygen partial pressure on structural, electrical, and optical properties of Al-doped $\mathrm{ZnO}$ film prepared by the ion beam co-sputtering method. J. Mater. Sci. 2013, 48, 1225-1230. [CrossRef]

18. Hsu, J.-C.; Lin, Y.-H.; Wang, P.W.; Chen, Y.-Y. Spectroscopic ellipsometry studies on various zinc oxide films deposited by ion beam sputtering at room temperature. Appl. Opt. 2012, 51, 1209-1215. [CrossRef]

19. Chen, Y.-Y.; Wang, P.W.; Hsu, J.-C.; Lee, C.-Y. Post-annealing properties of aluminum-doped zinc oxide films fabricated by ion beam co-sputtering. Vacuum 2013, 87, 227-231. [CrossRef]

20. Woollam, J.A.; Bungay, C.L.; Tiwald, T.E.; Liphardt, M.M.; Synowicki, R.A.; Pribil, G.K.; Herzinger, C.M.; Johs, B.D.; Hilfiker, J.N. Sample Analysis Methodology Utilizing Electromagnetic Radiation. U.S. Patent No. 7,385,697, 10 June 2008.

21. Gong, L.; Ye, Z.; Lu, J.; Zhu, L.; Huang, J.; Gu, X.; Zhao, B. Highly transparent conductive and near-infrared reflective $\mathrm{ZnO}: \mathrm{Al}$ thin films. Vacuum 2010, 84, 947-952. [CrossRef]

22. Kim, H.; Gilmore, C.M.; Pique, A.; Horwitz, J.S.; Mattoussi, H.; Murata, H.; Kafafi, Z.H.; Chrisey, D.B. Electrical, optical, and structural properties of indium-tin-oxide thin films for organic light-emitting devices. J. Appl. Phys. 1999, 86, 6451. [CrossRef]

23. Aspnes, D.E.; Theeten, J.B.; Hottier, F. Investigation of effective-medium models of microscopic surface roughness by spectroscopic ellipsometry. Phys. Rev. B 1979, 20, 3292. [CrossRef]

24. Fujiwara, H. Spectroscopic Ellipsometry: Principles and Applications; John Wiley \& Sons: Hoboken, NJ, USA, 2007.

25. Tseng, K.-S.; Lo, Y.-L. Investigation into inhomogeneous electrical and optical properties of indium tin oxide film using spectroscopic ellipsometry with multi-layer optical models. Opt. Mater. Express 2014, 4, 43-56. [CrossRef]

26. D'Elia, S.; Scaramuzza, N.; Ciuchi, F.; Versace, C.; Strangi, G.; Bartolino, R. Ellipsometry investigation of the effects of annealing temperature on the optical properties of indium tin oxide thin films studied by Drude-Lorentz model. Appl. Surf. Sci. 2009, 255, 7203-7211. [CrossRef] 
27. Hamberg, I.; Granqvist, C.G. Evaporated Sn-doped $\operatorname{In}_{2} \mathrm{O}_{3}$ films: Basic optical properties and applications to energy-efficient windows. J. Appl. Phys. 1986, 60, R123. [CrossRef]

28. Steinhauser, J.; Faÿ, S.; Oliveira, N.; Vallat-Sauvain, E.; Ballif, C. Transition between grain boundary and intragrain scattering transport mechanisms in boron-doped zinc oxide thin films. Appl. Phys. Lett. 2007, 90, 142107. [CrossRef]

29. Tahar, R.B.H.; Ban, T.; Ohya, Y.; Takahashi, Y. Tin doped indium oxide thin films: Electrical properties. J. Appl. Phys. 1998, 83, 2631. [CrossRef]

30. Hsu, J.-C.; Lee, C.-C. Single- and dual-ion-beam sputter deposition of titanium oxide films. Appl. Opt. 1998, 37, 1171-1176. [CrossRef]

31. Jiang, Y.; Bahlawane, N. Effect of nucleation and growth kinetics on the electrical and optical properties of undoped ZnO films. J. Phys. Chem. C 2010, 114, 5121-5125. [CrossRef]

32. Minami, T.; Hanato, H.; Shooji, S.; Takata, S. The stability of zinc oxide transparent electrodes fabricated by RF magnetron sputtering. Thin Solid Films 1984, 111, 167-174. [CrossRef]

33. Haug, F.-J.; Geller, Z.; Zogg, H.; Tiwari, A.N.; Vignali, C. Influence of deposition conditions on the thermal stability of ZnO:Al films grown by RF magnetron sputtering. J. Vac. Sci. Technol. A 2001, 19, 171. [CrossRef]

34. Kim, K.-K.; Tampo, H.; Song, J.-O.; Seong, T.-Y.; Park, S.-J.; Lee, J.-M.; Kim, S.-W.; Fujita, S.; Niki, S. Effect of rapid thermal annealing on $\mathrm{Al}$ doped $\mathrm{n}-\mathrm{ZnO}$ films grown by RF-magnetron sputtering. Jpn. J. Appl. Phys. 2005, 44, 4776-4779. [CrossRef]

35. Kittel, C. Introduction to Solid State Physics, 5th ed.; Wiley: Hoboken, NJ, USA, 1976.

36. Guglielmi, M.; Menegazzo, E.; Paolizzi, M.; Gasparro, G.; Ganz, D.; Pütz, J.; Aegerter, M.A.; Hubert-Pfalzgraf, L.; Pascual, C.; Durán, A.; et al. Sol-gel deposited Sb-doped tin oxide films. J. Sol-Gel Sci. Technol. 1998, 13, 679-683. [CrossRef]

37. Kuprenaite, S.; Abrutis, A.; Kubilius, V.; Murauskas, T.; Saltyte, Z.; Plausinaitiene, V. Effects of annealing conditions and film thickness on electrical and optical properties of epitaxial Al-doped ZnO films. Thin Solid Films 2016, 599, 19-26. [CrossRef]

38. Singh, A.V.; Mehra, R.M.; Buthrath, N.; Wakahara, A.; Yoshida, A. Highly conductive and transparent aluminum-doped zinc oxide thin films prepared by pulsed laser deposition in oxygen ambient. J. Appl. Phys. 2001, 90, 5661. [CrossRef]

39. Lu, J.; Ye, Z.; Zeng, Y.; Zhu, L.; Wang, L.; Yuan, J.; Zhao, B.; Liang, Q. Structural, optical, and electrical properties of $(\mathrm{Zn}, \mathrm{Al}) \mathrm{O}$ films over a wide range of compositions. J. Appl. Phys. 2006, 100, 073714. [CrossRef]

40. Tan, S.T.; Chen, B.J.; Sun, X.W.; Fan, W.J.; Kwok, H.S.; Zhang, X.H.; Chua, S.J. Blueshift of optical band gap in ZnO thin films grown by metal-organic chemical-vapor deposition. J. Appl. Phys. 2005, 98, 013505. [CrossRef]

41. Sernelins, B.E.; Berggren, K.-F.; Jin, Z.-C.; Hamberg, I.; Granqvist, C.G. Band-gap tailoring of ZnO by means of heavy Al doping. Phys. Rev. B 1988, 37, 10244. [CrossRef]

42. Tauc, J.; Grigorovici, R.; Vancu, A. Optical properties and electronic structure of amorphous germanium. Phys. Status Solidi B 1966, 15, 627-637. [CrossRef]

43. Chinta, P.V.; Lozano, O.; Wadekar, P.V.; Hsieh, W.C.; Seo, H.W.; Yeh, S.W.; Liao, C.H.; Tu, L.W.; Ho, N.J.; Zhang, Y.S.; et al. Evolution of metallic conductivity in epitaxial $\mathrm{ZnO}$ thin films on systematic $\mathrm{Al}$ doping. J. Electron. Mater. 2017, 46, 2030-2039. [CrossRef]

44. Yamada, T.; Makino, H.; Yamamoto, N.; Yamamoto, T. Ingrain and grain boundary scattering effects on electron mobility of transparent conducting polycrystalline Ga-doped ZnO films. J. Appl. Phys. 2010, 107, 123534. [CrossRef]

45. Nomoto, J.; Makino, H.; Yamamoto, T. Carrier mobility of highly transparent conductive Al-doped ZnO polycrystalline films deposited by radio-frequency, direct-current, and radio-frequency-superimposed direct-current magnetron sputtering: Grain boundary effect and scattering in the grain bulk. J Appl. Phys. 2015, 117, 045304. [CrossRef]

46. Knoops, H.C.M.; Van De Loo, B.W.H.; Smit, S.; Ponomarev, M.V.; Weber, J.-W.; Sharma, K.; Kessels, W.M.M.; Creatore, M. Optical modeling of plasma-deposited $\mathrm{ZnO}$ films: Electron scattering at different length scales. J. Vac. Sci. Technol. A 2015, 33, 021509. [CrossRef]

47. Pei, Z.; Zhang, X.; Zhang, G.; Gong, J.; Sun, C.; Huang, R.; Wen, L. Transparent conductive ZnO:Al thin films deposited on flexible substrates prepared by direct current magnetron sputtering. Thin Solid Films 2006, 497, 20-23. [CrossRef] 
48. Lee, C.-C.; Hsu, J.-C.; Wong, D.-H. The characteristics of some metallic oxides prepared in high vacuum by ion beam sputtering. Appl. Surf. Sci. 2001, 171, 151-156. [CrossRef]

49. Macleod, H.A. Thin-Film Optical Filter, 4th ed.; CRC Press: Boca Raton, FL, USA, 2010.

(c)

(C) 2018 by the authors. Licensee MDPI, Basel, Switzerland. This article is an open access article distributed under the terms and conditions of the Creative Commons Attribution (CC BY) license (http:/ / creativecommons.org/licenses/by/4.0/). 